\title{
Pemanfaatan Metode Joyfull Learning Dalam Multimedia Pembelajaran Interaktif Bahasa Inggris
}

\author{
Daniel Rutdjiono', Khoirur Rozikin ${ }^{2}$, Nuris Dwi Setiawan ${ }^{3}$ \\ 1,2,3Universitas Sains dan Teknologi Komputer \\ Jl.Majapahit 605 Semarang, \\ e-mail: danielrudjiono@gmail.com ${ }^{1}$, khoirur@stekom.ac.id ${ }^{2}$, Setyawan_dw@ stekom.ac.id $^{3}$
}

\begin{tabular}{ll}
\hline ARTICLE INFO & ABSTRACT \\
\cline { 2 - 3 } Article history: & $\begin{array}{l}\text { The development of science and technology } \\
\text { increasingly encourages reform efforts in the } \\
\text { teaching and learning process, teachers are required } \\
\text { Received 23 October 2021 } \\
\text { Accepted 4 November 2021 } \\
\text { to be able to use and create more innovative learning } \\
\text { media. SMP IT Cahaya Ummat Karangjati is one of } \\
\text { the Islamic educational institutions which in the } \\
\text { learning process is still using conventional methods. } \\
\text { This causes students to feel bored and less active in } \\
\text { the learning process, so it is necessary to make new } \\
\text { innovations in terms of learning media. } \\
\text { The solution offered in this study is an interactive } \\
\text { learning media with the Joyful Learning method. } \\
\text { The Joyful Learning method is a very good method } \\
\text { used to involve students in learning the material that } \\
\text { has been delivered considering that students are less } \\
\text { active in the learning process. The results of this } \\
\text { study are designed to provide learning innovations, } \\
\text { especially for English class VII semester } 2 \text { SMP IT } \\
\text { Cahaya Ummat Karangjati. In addition, with the } \\
\text { interactive learning media, it is expected that } \\
\text { students will become more active in the learning } \\
\text { process and can increase learning motivation so as to } \\
\text { increase learning outcomes. } \\
\text { Keywords: Multimedia, Learning Media, Joyful } \\
\text { Learning, English }\end{array}$ \\
\hline
\end{tabular}

\begin{abstract}
Abstrak
Perkembangan ilmu pengetahuan dan teknologi semakin mendorong upaya-upaya pembaruan dalam proses belajar mengajar, guru dituntut agar mampu menggunakan maupun membuat media pembelajaran yang lebih inovatif. SMP IT Cahaya Ummat Karangjati merupakan salah satu lembaga pendidikan Islam yang dalam proses pembelajaran masih menggunakan metode konvensional. Hal ini menyebabakan siswa mengalami kebosanan dan kurang aktif dalam proses pembelajaran, sehingga perlu dibuatnya inovasi baru dalam hal media pembelajaran.

Solusi yang ditawarkan pada penelitian ini adalah sebuah media pembelajaran interaktif dengan metode Joyfull Learning. Metode Joyfull Learning adalah metode yang sangat baik di gunakan untuk melibatkan peserta didik dalam mempelajari materi yang telah disampaikan mengingat siswa kurang aktif dalam proses pembelajaran. Hasil penelitian ini dirancang untuk memberikan inovasi pembelajaran khususnya mata pelajaran Bahasa Inggris kelas VII semester 2 SMP IT Cahaya Ummat Karangjati. Selain itu, dengan adanya media pembelajaran interaktif
\end{abstract}


diharapkan peserta didik menjadi lebih aktif dalam proses pembelajaran dan dapat meningkatkan motivasi belajar sehingga membuat hasil belajar meningkat.

Kata Kunci : Multimedia, Media Pembelajaran, Joyfull Learning, Bahasa Inggris

\section{Pendahuluan}

Pada saat ini perkembangan ilmu pengetahuan dan teknologi semakin mendorong upayaupaya pembaruan dalam pemanfaatan hasil-hasil teknologi dalam proses belajar mengajar. Di Era sekarang ini, guru dituntut agar mampu membuat dan mengaplikasikan media pembelajaran yang menyenangkan sehingga proses belajar mengajar menjadi lebih menarik[1].

Menurut UU No. 20 Tahun 2003 tentang Sisdiknas Pasal 1 Ayat 20 "Pembelajaran merupakan proses interaksi peserta didik dengan pendidik dan sumber belajar pada suatu lingkungan belajar"'[2]. Dalam proses pembelajaran keberadaan sumber belajar sangatlah penting untuk mendukung kelancaran proses belajar mengajar. Salah satu komponen utama pendukung sumber belajar adalah adanya media pembelajaran. Media pembelajaran adalah media yang memungkinkan terwujudnya hubungan langsung antara karya seseorang pengembang mata pelajaran dengan siswa[3]. SMP IT Cahaya Ummat Karangjati merupakan salah satu lembaga pendidikan Islam yang berlokasi di Jalan Kalinjaro, Kelurahan Karangjati, Kecamatan Bergas, Kabupaten Semarang. Lembaga pendidkan ini didirikan pada Tahun 2004, berada dibawah naungan Yayasan Sosial Dakwah Nur Hidayah.

Proses belajar mengajar SMPIT Cahaya Ummat Karangjati pada umumnya berjalan seperti biasa, yaitu adanya interaksi guru dengan murid. Namun ada beberapa hal yang menjadi fokus perhatian, yaitu pembelajaran Bahasa Inggris yang masih menggunakan metode yang konvensional. Hal ini menyebabakan siswa mengalami kebosanan dalam pembelajaran yang disampaikan oleh guru, sehingga pada pemahaman materi yang siswa terima menjadi tidak maksimal. Peserta didik hanya mendengarkan, mencatat dan menjawab apabila ditanya oleh guru dan kurang aktif dalam proses pembelajaran. Hal ini tentu saja akan mempengaruhi tujuan pembelajaran. Guna mengatasi masalah yang telah dikemukakan di atas salah satunya dengan dibuatnya media pembelajaran interaktif menggunakan metode Joyfull Learning[4].

Metode pembelajaran Joyfull Learning merupakan metode yang sangat baik di gunakan untuk melibatkan peserta didik dalam mempelajari materi yang telah disampaikan[5].

\section{Tinjauan Pustaka}

Menurut (Latuheru, 1988) media pembelajaran adalah bahan, alat, maupun metode/teknik yang digunakan dalamkegiatan belajar mengajar, dengan maksud agar proses interaksi komunikasi edukatif antara guru dan anak didik/warga belajar dapat berlangsung secara tepatguna danberdayaguna[6]. Media interaktif merupakan sistem penyajian bahan pembelajaran yang direkam (visual, suara dan video) dan ditampilkan dengan kontrol komputer[7].

Multimedia adalah pemanfaatan komputer untuk membuat dan menggabungkan teks, grafik, audio, gambar bergerak (video dan animasi) dengan menggabungkan link dan tool yang memungkinkan pemakai melakukan navigasi, berinteraksi, berkreasi dan berkomunikasi, menggabungkan link dan tool yang memungkinkan pemakai melakukan navigasi, berinteraksi, berkreasi dan berkomunikasi[8].

Salah satu strategi pembelajaran yang diharapkan mampu untuk meningkatkan hasil belajar adalah dengan menggunakan strategi pembelajaran yang menyenanngkan (Joyful Learning). Joyful learning merupakan strategi pembelajaran untuk mengembangkan keterampilan dan pemahaman siswa, dengan penekanan pada belajar sambil bekerja (learning by doing). Pembelajaran menyenangkan atau juga diistilahkan dengan joyful learning merupakan strategi, konsep dan praktik pembelajaran yang sinergi dengan pembelajaran bermakna, pembelajaran kontekstual, teori kontruktivisme, pembelajaran aktif (active learning) dan psikologi perkembangan anak. Joyful Learning dapat membantu mengembangkan kemampuan berpikir, membangun sendiri konsep materi pelajaran serta kemampuan merumuskan kesimpulan pada siswa dan menghadapkan siswa kepada suatu keadaan yang menyenangkan sehingga dapat

JURNAL ILMIAH ELEKTRONIKA DAN KOMPUTER Vol. 14, No. 2, Desember 2021 : 189 - 197 
membuat siswa menyukai materi yang diberikan karena proses belajar didesain lebih dinamis, menekankan hal-hal visual, dan menyenangkan. Joyful Learning berpengaruh besar pada prestasi siswa, prestasi siswa akan meningkat dengan digunakannya Joyful Learning[9].

\section{Metode Penelitian}

\subsection{Tahapan Penelitian}

Penelitian ini memiliki tahapan-tahapan yaitu tahapan analisis kebutuhan, tahapan perancangan dan tahapan implementasi. Sebelum dilakukannya uji coba aplikasi, dilakukan terlebih dahulu validasi terhadap media pembelajaran yang akan dihasilkan. Untuk validator materi yaitu 2 orang guru Bahasa Inggris , untuk validator media 2 orang dosen sistem komputer, untuk validator aplikasi dilakukan pada 30 orang siswa SMP IT Cahaya Ummat Karangjati untuk mengetahui respon siswa terhadap media. Data yang diperoleh dari penelitian ini berupa data kuantitatif dan data kualitatif. Data kuantitatif diperoleh dari data kuesioner beupa skor penilaian, sedangkan data kualitatif diperoleh dari hasil wawancara, kritik, dan saran yang ada pada kuesioner. Analisis data dari angket validasi materi, media dan aplikasi dilakukan dengan langkah-langkah sebagai berikut:

a. Menjumlahkan banyaknya tanda centang dan skor jawaban pada setiap kolom dalam satu item pertanyaan.

b. Menjumlahkan skor ideal dalam satu item pertanyaan.

c. Menuliskan besarnya persentase dalam setiap item, kemudian besarnya persentase akan digunakan untuk menentukan kriteria kevalidan produk/ aplikasi. Dalam menghitung persentase dari masing-masing item dalam angket validasi dapat dituliskan dengan Persamaan 1.

$$
\mathrm{P}=\frac{\sum \mathrm{x}}{\sum \mathrm{xi}} \mathrm{x} 100 \%
$$

Keterangan:

$\mathrm{P}=$ Persentase validitas

$\Sigma \mathrm{x}=$ Jumlah skor jawaban responden dalam satu item

$\Sigma x i=$ Jumlah skor ideal dalam satu item pertanyaan

$100 \%=$ Konstanta

Tabel 1. Kriteria Validitas Produk/Aplikasi

\begin{tabular}{c|l}
\hline Persentase & \multicolumn{1}{c}{ Kriteria } \\
\hline $90 \%-100 \%$ & $\begin{array}{l}\text { Sangat Valid/ } \\
\text { dapat digunakan tanpa revisi }\end{array}$ \\
\hline $75 \%-89 \%$ & $\begin{array}{l}\text { Valid/ } \\
\text { dapat digunakan tanpa revisi }\end{array}$ \\
\hline $65 \%-74 \%$ & $\begin{array}{l}\text { Cukup Valid/ } \\
\text { dapat digunakan dengan sedikit revisi }\end{array}$ \\
\hline $40 \%-64 \%$ & $\begin{array}{l}\text { Kurang Valid/ } \\
\text { dapat digunakan dengan banyak revisi }\end{array}$ \\
\hline $0 \%-39 \%$ & $\begin{array}{l}\text { Tidak Valid/ } \\
\text { revisi total, belum dapat digunakan }\end{array}$ \\
\hline
\end{tabular}

Sumber: Arikunto (2010)

Hasil analisis yang diperoleh digunakan untuk menarik kesimpulan valid tidaknya suatu produk media pembelajaran interaktif Bahasa Inggris. 


\subsection{Flowchart Multimedia}

Flowchart dalam multimedia merupakan sebuah diagram dengan simbol - simbol grafis yang menyatakan aliran proses yang menampilkan langkah - langkah yang disimbolkan dalam bentuk kotak, beserta urutannya dengan menghubungkan masing - masing langkah tersbut menggunakan tanda panah. Diagram ini bisa memberi gambaran selangkah demi selangkah jalannya suatu proses.

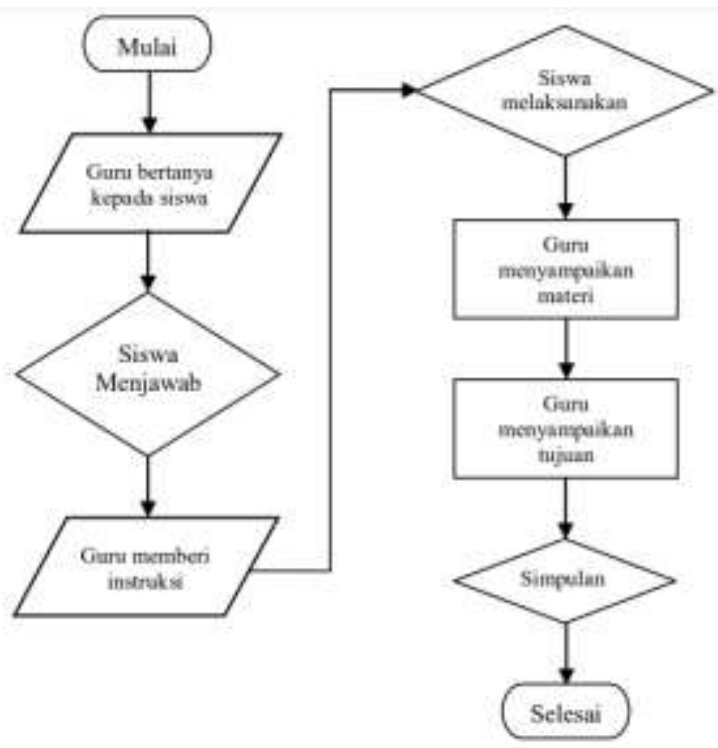

Gambar 1. Flowchart sistem pembelajaran Sumber : Penulis, 2021

\subsection{Desain output}

Pada proses penyusunan media pembelajaran interaktif, penulis menyajikan materi tersebut kedalam sebuah aplikasi multimedia pembelajaran. Kemudian setiap materi diberi penjelasan dan contoh berupa animasi 2 dimensi. Hal ini dimaksudkan agar dapat memudahkan siswa dalam belajar dan memahami maksud materi yang disajikan. Selain penyajian materi, penulis juga menyajikan indikator pemahaman penguasaan materi. Grafis yang disajikan disesuaikan dengan tema dasar dari aplikasi multimedia yang dirancang dalam multimedia ini, terlebih dahulu dibuat sketsa desain aplikasinya. Berikut adalah beberapa desain halaman dari aplikasi :

1. Halaman Awal

Halaman awal berisi gambar gedung sekolah, logo sekolah, nama instansi pendidikan SMP IT Cahaya Ummat Karangjati yang dianimasikan dengan Classic Tween dan SWiSH movie.

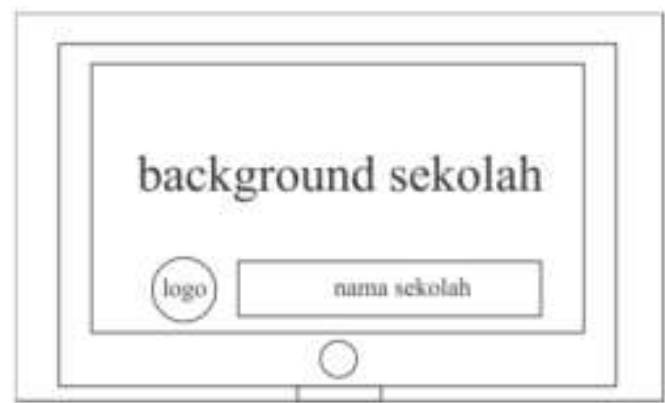

Gambar 2. Layout Halaman Awal

Sumber : Penulis, 2021

JURNAL ILMIAH ELEKTRONIKA DAN KOMPUTER Vol. 14, No. 2, Desember 2021: 189 - 197 
2. Halaman Menu

Halaman menu menampilkan judul media pembelajaran dan menu utama. Terdapat 3 menu utama yaitu menu profil, materi, dan evaluasi. Masing - masing menu diisikan script untuk menuju ke halaman selanjutnya.

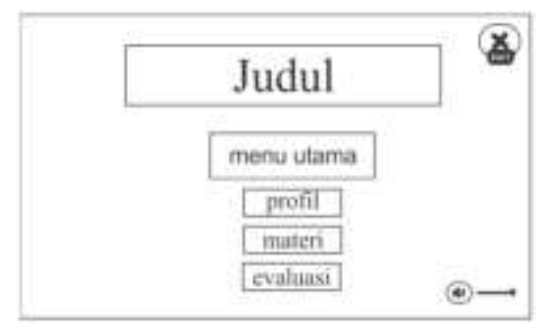

Gambar 3. Layout Halaman Menu

Sumber : Penulis, 2021

3. Halaman Materi

Halaman materi berisi 7 (tujuh) materi, yang dapat dipilih. Yaitu materi asking \& giving, shopping list, announcement, instruction, congratulation, descriptive text, dan procedure text. Menggunakan gambar papan kayu sebagai tombol materi, apabila ditekan tombol akan mengecil. Apabila di klik akan menuju pembahasan materi yang dimaksud. Tombol home ditambahkan untuk kembali ke halaman menu.

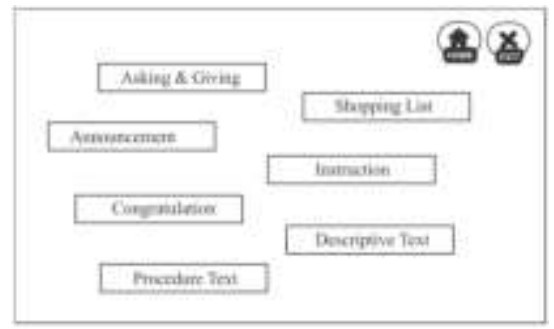

Gambar 4. Layout Halaman Materi

Sumber : Penulis, 2021

4. Halaman Penjelasan Materi

Halaman penjelasan dari contoh materi berisi penjelasan contoh materi yang dimaksud sedangkan contoh materi berisi contoh dari materi yang dijelaskan dengan animasi 2 dimensi serta ditambahkan suara. Pada bagian kanan gambar bingkai kayu terdapat tombol navigasi yaitu materi untuk kembali ke halaman materi, next untuk menuju ke contoh materi selanjutnya, back untuk kembali ke contoh materi sebelumnya, dan max untuk memperbesar tampilan layar.

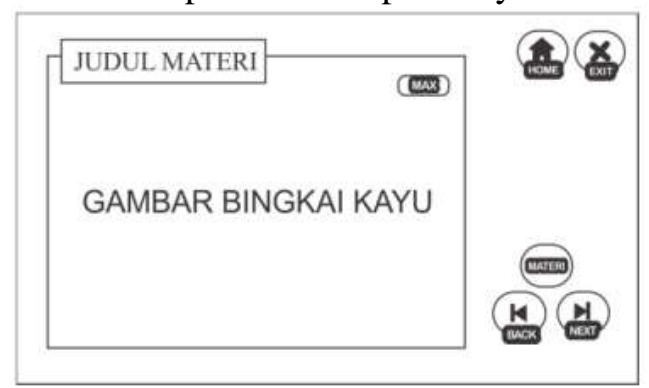

Gambar 5. Layout Halaman Penjelasan Materi Sumber : Penulis, 2021

5. Halaman Evaluasi

Pemanfaatan Metode Joyfull Learning Dalam Multimedia Pembelajaran Interaktif Bahasa Inggris 
Halaman evaluasi berisi soal latihan materi pelajaran yang telah diajarkan. Berisi 20 (duapuluh) soal pilihan ganda dengan sistem koreksi akhir. Ketika selesai memilih jawaban, secara otomatis akan bergeser ke pertanyaan selanjutnya. Menu login disediakan untuk masuk ke dalam soal evaluasi.

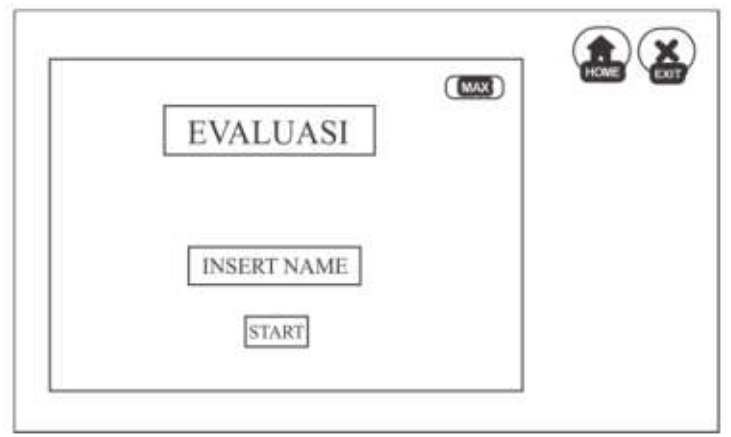

Gambar 6. Layout Halaman Evaluasi

Sumber : Penulis, 2021

\section{Hasil dan Pembahasan}

\subsection{Hasil}

Pada tahapan ini adanya media pembelajaran interaktif Bahasa Inggris materi sistem pencernaan makanan manusia yang selanjutnya bisa diuji ke validannya oleh beberapa validator dan beberapa siswa sebagai pengguna media aplikasi tersebut. Berikut ini disajukan tampilan halaman awal, konten pada media pembelajaran interaktif Bahasa Inggris .

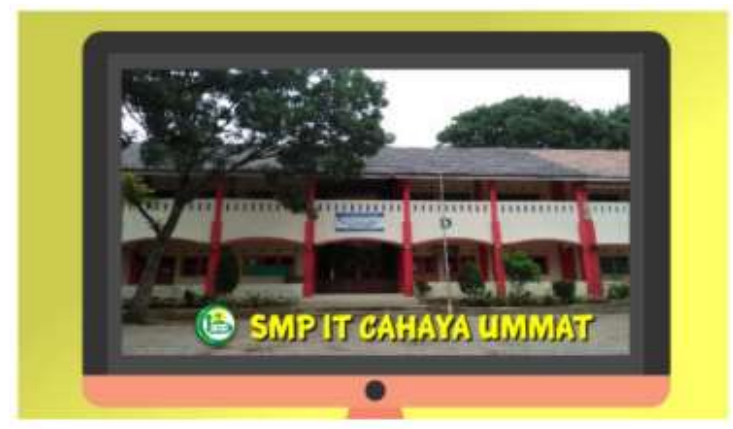

Gambar 8. Tampilan Awal Media Pembelajaran Sumber : Penulis, 2021

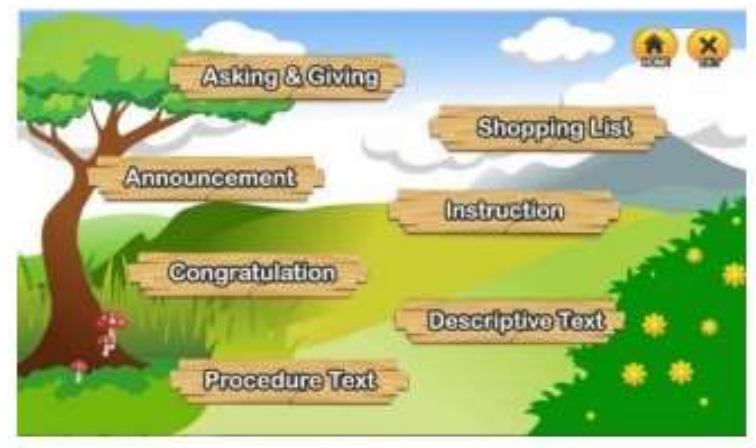

Gambar 10. Menu Materi Media Pembelajaran Sumber : Penulis, 2021

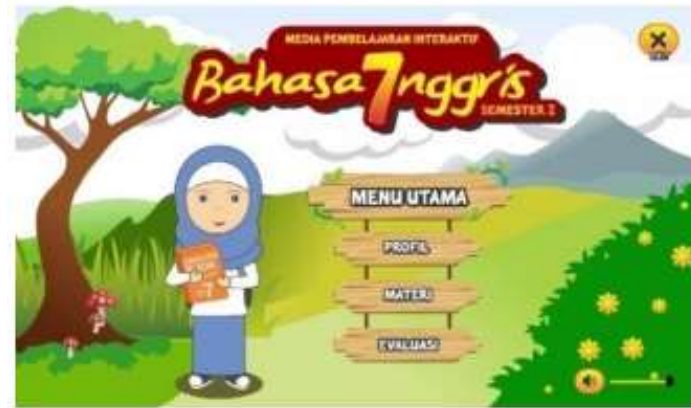

Gambar 9. Menu Utama Media Pembelajaran Sumber : Penulis, 2021

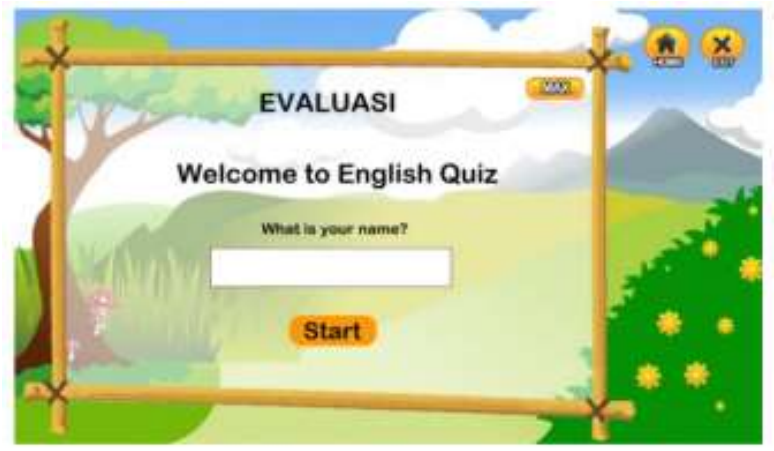

Gambar 11. Menu Evaluasi Media Pembelajaran Sumber : Penulis, 2021

\subsection{Pembahasan}

JURNAL ILMIAH ELEKTRONIKA DAN KOMPUTER Vol. 14, No. 2, Desember 2021 : 189-197 
1. Validasi Ahli

Berdasarkan perhitungan validitas oleh validator media, penilaian untuk aspek media dan aspek komunikasi visual adalah sangat baik, dengan persentase kelayakan 92\%, sedangkan untuk aspek Kemudahan Penggunaan 86\% sehingga kesimpulan yang diperoleh dari Kemudahan penggunaan dan komunikasi visual adalah sangat valid. Hasil validitas media oleh validataor media dapat dilihat dalam Tabel di bawah ini :

Tabel 2. validitas oleh validator media

\begin{tabular}{|l|c|l|}
\hline \multicolumn{1}{|c|}{ Kriteria } & Presentase & \multicolumn{1}{c|}{ Kesimpulan } \\
\hline Komunikasi Visual & $92 \%$ & Sangat Valid dapat digunakan Tanpa Revisi \\
\hline Kemudahan penggunaan & $86 \%$ & Valid dapat digunakan tanpa Revsi \\
\hline
\end{tabular}

2. Validasi Guru

Data hasil validasi ahli materi yang diperoleh dari 2 orang guru matapelajaran Bahasa Inggris pada SMP IT Cahaya Ummat Karangjati. Validasi yang dilakukan berdasarkan kepada kesesuaian materi, penyajian materi, dan cakupan materi. Berdasarkan perhitungan validitas oleh validator materi, diperoleh persentase penilaian untuk kesesuaian materi $82 \%$, penyajian materi $80 \%$, dan cakupan materi $92 \%$. Sehingga kesimpulan media untuk semua aspek penilaian oleh validaor materi adalah sangat valid. Hasil validitas disajikan dalam Tabel di bawah ini :

Tabel 3. validitas materi pembelajaran

\begin{tabular}{|l|c|l|}
\hline \multicolumn{1}{|c|}{ Kriteria } & Presentase & \multicolumn{1}{c|}{ Kesimpulan } \\
\hline Kesesuaian Materi & $82 \%$ & Valid dapat digunakan tanpa Revsi \\
\hline Penyajian Materi & $80 \%$ & Valid dapat digunakan tanpa Revsi \\
\hline Cakupan Materi & $92 \%$ & Sangat Valid dapat digunakan Tanpa Revisi \\
\hline
\end{tabular}

3. Validasi Pengguna

Subyek uji coba penelitian ini adalah siswa/i SMP IT Cahaya Ummat Karangjati. Data yang di dapat adalah data kualitatif dan data kuantitatif. Berdasarkan hasil perhitungan yang dieroleh untuk menentukan respon dari siswa, penilaian diukur dari isi materi, pembelajaran, dan tampilan media pembelajaran. Nilai yan diperoleh berupa $86 \%$ isi materi, $82 \%$ pembelajaran, dan $84 \%$ tampilan media pembelajaran. Hasil dapat dilihat dalam tabel dibawah ini:

Tabel 4. Respon Siswa

\begin{tabular}{|l|c|l|}
\hline \multicolumn{1}{|c|}{ Kriteria } & Presentase & \multicolumn{1}{c|}{ Kesimpulan } \\
\hline Isi Materi & $86 \%$ & Valid dapat digunakan tanpa Revsi \\
\hline Pembelajaran & $82 \%$ & Valid dapat digunakan tanpa Revsi \\
\hline Tampilan Media & $84 \%$ & Valid dapat digunakan Tanpa Revisi \\
\hline
\end{tabular}

Pemanfaatan Metode Joyfull Learning Dalam Multimedia Pembelajaran Interaktif Bahasa Inggris 


\section{Kesimpulan Dan Saran}

\subsection{Kesimpulan}

Berdasarkan hasil pembahasan tugas akhir mengenai Perancangan Media Pembelajaran interaktif Bahasa Inggris dengan Metode Joyfull Learning yang dilakukan di SMP IT Cahaya Ummat Karangjati dapat ditarik kesimpulan sebagai berikut :

1. Dengan adanya media pembelajaran Interaktif dengan metode joyfull learning, maka kegiatan belajar mengajar dapat lebih efektif karena metode ini dapat membantu mengembangkan kemampuan berpikir, membangun sendiri konsep materi pelajaran serta kemampuan merumuskan kesimpulan pada siswa, dan menghadapkan siswa pada suatu keadaan yang menyenangkan sehingga dapat membuat siswa menyukai materi yang diberikan.

2. Media Pembelajaran Interaktif dapat membantu siswa meningkatkan motivasi belajar dan menjadikan siswa lebih aktif dalam proses pembelajaran sehingga dapat membuat hasil belajar peserta didik meningkat.

\subsection{Saran}

Berdasarkan hasil pembahasan dan kesimpulan diatas, maka saran yang dapat diberikan penulis adalah sebagai berikut :

1. Diharapkan untuk peneliti selanjutnya dapat membuat media pembelajaran yang lebih baik lagi dengan metode yang lainnya.

2. Perlu diadakannya pelatihan untuk tenaga pengajar dan ketersediaan sarana dan prasarana untuk mendukung pembelajaran yang lebih inovatif.

\section{Daftar Pustaka}

[1] Dani Kurniawan. 2018. "Komunikasi Model Laswell Dan Stimulus-Organism-Response Dalam Mewujudkan Pembelajaran Menyenangkan". Vol. 2, No. 1. (2018). Jurnal Komunikasi Pendidikan, Sukoharjo, Indonesia.

[2] Rizky Rinaldy Inkiriwang. 2020. "Kewajiban Negara Dalam Penyediaan Fasilitas Pendidikan Kepada Masyarakat Menurut Undang-Undang Nomor 20 Tahun 2003 Tentang Sistem Pendidkan Nasional”. Vol. 8, No. 2. (2020). Jurnal Elektronik Bagian Hukum Keperdataan, Manado, Indonesia.

[3] Talizaro Tafonao. 2018. "Peranan Media Pembelajaran Dalam Meningkatkan Minat Belajar Mahasiswa”. Vol. 2, No. 1. (2018). Jurnal Komunikasi Pendidikan, Sukoharjo, Indonesia.

[4] Sutatik. 2021. "Meningkatkan Minat Belajar Seni Budaya Melalui Joyful Learning Sebagai Media Pembelajaran Pada Siswa Kelas IX-A Semester Ganjil Di SMP Negeri 1 Ngadirojo Kabupaten Pacitan Tahun Pelajaran 2019/2020”. Vol. 6, No. 1. (2021). Jurnal Refleksi Pembelajaran, Madiun, Indonesia.

[5] Refni Ramadani. 2020. "Pengaruh Model Pembelajaran Joyful Learning Menggunakan Media Online Terhadap Anak ADHD di Masa Pandemi COVID-19”. Vol. 1, No. 1. (2020). Seminar Nasional Pendidikan, Surabaya, Indonesia.

[6] Iqbal Wahyu Romadhon. 2020. "Pengembangan Media Pembelajaran Simulasi Pada Keterampilan Menggosok Gigi Anak Tunagrahita Dalam Model Pembelajaran Joyfull Learning”. Vol. 5, No. 1. (2020). Jurnal IT-Edu (Information Technology and Education), Surabaya, Indonesia.

[7] Muhammad Fauzan Sidik. 2021. "Penerapan Teknologi Augmented Reality Pada Media Pembelajaran Interaktif Berbasis Android Untuk Materi Instalasi Jaringan Komputer". Vol.8, No.12. (2021). Jurnal Teknologi Informasi Komunikasi, Jogya, Indonesia.

[8] Ruqiah Ganda Putri Panjaitan. 2021. "Multimedia Interaktif Berbasis Game Edukasi Sebagai Media Pembelajaran Materi Sistem Pernapasan Di Kelas Xi Sma”. Vol. 8, No. 1. (2021). Jurnal Pendidikan Sains Indonesia, Aceh, Indonesia.

JURNAL ILMIAH ELEKTRONIKA DAN KOMPUTER Vol. 14, No. 2, Desember 2021: 189-197 
[9] Safira Datu. 2021. "Pengaruh Model Pembelajaran Kontekstual dengan Strategi Joyful Learning pada Pembelajaran Jarak Jauh terhadap Kemampuan Pemahaman Konsep Matematis Peserta Didik SMP Negeri 97 Jakarta". Vol. 5, No. 2. (2021). Jurnal Riset Pembelajaran Matematika Sekolah, Jakarta, Indonesia. 